\section{The H1N1 birthday cake: To blow or not to blow}

Re: "Estimated epidemiologic parameters and morbidity associated with pandemic H1N1 influenza." As the traditional ceremony culminated at a colleague's recent half-century birthday party, the cake was brought out with candles ablaze. Then a rather unusual ritual ensued. The honouree removed the first lit candle and placed it in a cup of water. This act was repeated 49 more times. While we could determine no obvious suggestion of cerebral ischemia, we were speculating that perhaps certain medications were not quite in the therapeutic range. When asked, the honouree explained: "In the age of pandemics, do you really want someone to forcibly exhale over an entire birthday cake that you are about to eat?" So, if one attends a birthday party with a less savvy host, then to eat or not to eat should be the question.

Maxwell B. Sauder, MD Candidate 2011 McMaster University, Hamilton, Ont.

\section{REFERENCES}

1. Tuite AR, Greer AL, Whelan M, et al. Estimated epidemiologic parameters and morbidity associated with pandemic H1N1 influenza. CMAJ 2009;182: 131-6.

For the full letter, go to: www.cmaj.ca/cgi/eletters /cmaj.091807v1\#268016

DOI:10.1503/cmaj.110-2032

\section{The severity of H1N1}

Timely information about the pandemic (H1N1) 2009 influenza would have been welcome by both the medical community and the public. Although it is expected that reports such as that from O'Riordan and colleagues ${ }^{1}$ would eventually emerge in Canada, it was apparent to many frontline general practitioners that the patients suffering from this infection and who were returning from Mexico to Canada in April and May 2009 were not suffering an overly aggressive illness. O'Riordan's findings are consistent with the above, but now, in the scientific eye, limitations of such research are important to recognize.

For example, it is not apparent from the paper that significant differences in age between pandemic and seasonal infection groups were to be adjusted prior to the assessment for severity of illness and outcome. Having access to early and timely data if appropriately collated and analyzed would have been of potential value to all. In future planning for potential pandemics, acquisition of such data from academic centres and public health could be speedily groomed, analyzed and disseminated. Support for such endeavours is well within the mandate of our national health agencies. We will have plenty of years ahead of influenza activity in order to give such data gathering the preliminary assessments that are required to have an excellent model well in place ahead of time.

\section{Nevio Cimolai MD}

Children's and Women's Health Centre of British Columbia, Vancouver, BC

\section{REFERENCE}

1. O'Riordan S, Barton M, Yau Y, et al. Risk factors and outcomes among children admitted to hospital with pandemic H1N1 influenza. CMAJ 2010;182: 39-44.

For the full letter, go to: www.cmaj.ca/cgi/eletters /182/1/39\#265037

DOI:10.1503/cmaj.110-2024

\section{The role of medical witnesses}

Iacobucci and Hamilton's article ${ }^{1}$, which should be studied by every actual and potential medical witness, does much to encapsulate the situation in which doctors in court find themselves, but sadly does little to solve their dilemma. It correctly stresses the dedication of the law to the adversarial process and recognizes that the adversarial process is by and large inappropriate for the expert witness. Our role, they say, is "to assist the court by providing impartial testimony" — which will come as a surprise to many doctors and apparently to most lawyers practising as counsel. The subpoena that brings a doctor to court states explicitly that it is issued because the physician is expected to provide evidence for one side of the case or the other; it says nothing about being an impartial objective witness for the court. To demand, on the one hand, impartial objectivity and, on the other, submission to the adversarial process is conscription into the 100-yard dash wearing sea boots.

When everyone else in the court save the expert witness, and presumably the judge and jury, is by definition on one side or the other, it is asking a lot of the doctor/witness to be impartial and objective, a great rock above and apart from the turbulent torrents of adversariality. If the doctor is a witness for the court, then the doctor should be summoned by and for the court, not by one of the contending parties.

\section{H.E. Emson MD MA}

Saskatoon, Sask.

\section{REFERENCES}

1. Iacobucci $F$, Hamilton $G$. The Goudge Inquiry and the role of medical expert witnesses. CMAJ 2010; 182:53-6.

For the full letter, go to: www.cmaj.ca/cgi/eletters /182/1/53\#270360

DOI:10.1503/cmaj.110-2030

\section{Atypical femoral fractures}

Osteoporotic fracture is associated with significant morbidity and mortality. Rahmani and Morin have reviewed the evidence supporting the use of oral bisphosphonates as first line therapy for postmenopausal women and older men with osteoporosis and/or fragility fractures. ${ }^{1}$ Bisphosphonates reduce the risk of future fractures and their 10-year safety profile had appeared to be satisfactory. ${ }^{2}$ However, long-term bisphosphonate use has been reported to contribute to the presentation of atypical femoral fractures, raising concern about long-term safety.

We recently sought to examine this potential risk in Australia through a national survey (April-August 2009). 